\title{
Microstructural degradation of Electron Beam-Physical Vapour Deposition Thermal Barrier Coating during thermal cycling tracked by X-ray micro-computed tomography Dol:
}

10.1016/j.scriptamat.2018.04.010

\section{Document Version}

Accepted author manuscript

Link to publication record in Manchester Research Explorer

Citation for published version (APA):

Zhang, X., Zhao, Y., Withers, P., \& Xiao, P. (2018). Microstructural degradation of Electron Beam-Physical Vapour Deposition Thermal Barrier Coating during thermal cycling tracked by X-ray micro-computed tomography. Scripta Materialia. https://doi.org/10.1016/j.scriptamat.2018.04.010

Published in:

Scripta Materialia

\section{Citing this paper}

Please note that where the full-text provided on Manchester Research Explorer is the Author Accepted Manuscript or Proof version this may differ from the final Published version. If citing, it is advised that you check and use the publisher's definitive version.

\section{General rights}

Copyright and moral rights for the publications made accessible in the Research Explorer are retained by the authors and/or other copyright owners and it is a condition of accessing publications that users recognise and abide by the legal requirements associated with these rights.

\section{Takedown policy}

If you believe that this document breaches copyright please refer to the University of Manchester's Takedown Procedures [http://man.ac.uk/04Y6Bo] or contact uml.scholarlycommunications@manchester.ac.uk providing relevant details, so we can investigate your claim.

\section{OPEN ACCESS}




\begin{abstract}
The degradation of an Electron Beam-Physical Vapour Deposition Thermal Barrier Coating caused by thermal cycling at $1150^{\circ} \mathrm{C}$ has been followed in $3 \mathrm{D}$ non-destructively by timelapse X-ray micro-computed tomography $(\mu-\mathrm{CT})$. Quantitative analysis of X-ray $\mu$-CT virtual cross-sections on small samples are validated by destructive cross-sectional scanning electron microscopy (SEM) micrographs of larger ones. The evolution of thermally-grown oxide (TGO) is quantified. The TGO/bond coat interface roughness is measured in 3D. No significant rumpling is observed. Undulations are found locally at the interface of the asdeposited sample. Such undulations can increase in amplitude during cycling providing locations for interfacial cracks to initiate.
\end{abstract}

Key words: high temperature; turbine blade; $\beta$-(Ni, $\mathrm{Pt}) \mathrm{Al}$; interface; non-destructive

The application of thermal barrier coatings (TBCs) to single crystal nickel superalloys has enabled significant increases in the operating temperatures of turbine blades [1], thereby improving the efficiency of turbine engines. A typical TBC system generally consists of four layers: the superalloy substrate; the metallic bond coat; the thermally grown oxide (TGO) and the ceramic topcoat [2]. The lifetime of this multi-layer coating system is limited by coating spallation [3], to which various mechanisms contribute depending on both the coating materials and the loading conditions. Oxidation of the bond coat occurs at peak operating conditions (bond coat temperature $>700^{\circ} \mathrm{C}$ [2]), leading to the development of a thermally grown oxide (TGO). In addition, stress is developed due to mismatch in thermal expansion 
coefficients of the constituent layers [4]. For an Electron Beam-Physical Vapour Deposited (EB-PVD) TBC with a $\beta$-(Ni, Pt)Al bond coat, TGO rumpling under thermal cycling has been recognised as one of the primary mechanisms for interfacial delamination[5-10]. An investigation of TGO growth and the evolution of the interface under conditions representative of those in service will shed more light on the failure mechanisms of TBCs.

Most of the microstructural information collected to date regarding TBCs has been acquired using destructive cross-sectioning. This has two consequences. One is that specific features cannot be tracked as a function of thermal cycling since different samples are examined after different numbers of cycles. Another is that crucial features, such as interface cracks, can be introduced accidentally during sample preparation. As a non-destructive characterization method, X-ray $\mu$-CT has been used for microstructure investigation over multiple scales [11, 12]. Zhao et al. were the first to use time-lapse $\mu$-CT to follow the evolution of TGO formation and damage as a function of thermal exposure [13]. Ahmadian et al. revealed the 3D cracking characteristics in cycled air-plasma sprayed (APS) TBCs [14]. Subsequently, the displacement in a Pt-diffused $\gamma / \gamma^{\prime}$ bond coat has been mapped under cyclic exposure at $1200{ }^{\circ} \mathrm{C}$ using synchrotron X-ray $\mu$-CT and digital volume correlation (DVC) [15]. Recently, the residual stress distribution in an APS TBC was determined using finite element (FE) models developed from the 3D micrographs obtained by X-ray $\mu$-CT [16].

Here we employ time-lapse X-ray $\mu$-CT to track the evolution of the TGO and the TGO/bond coat interface in an EB-PVD TBC deposited on a $\beta-\mathrm{Ni}(\mathrm{Pt}) \mathrm{Al}$ bond coat during thermal cycling. After validation of the small sample geometry by comparison with destructive SEM images, our aim has been to use time-lapse X-ray $\mu$-CT to follow and quantify TGO growth and the development of interfacial roughness as a function of thermal exposure and to relate these to the features in the as-deposited sample. 
The test coupons were cut from a pristine turbine blade comprising an EB-PVD yttria stabilised zirconia (YSZ) topcoat, a $\beta-\mathrm{Ni}(\mathrm{Pt}) \mathrm{Al}$ bond coat and a CMSX-4 single-crystal superalloy substrate. The coupon was then ground to a rectangular matchstick with a crosssection diagonal length of $\sim 500 \mu \mathrm{m}$ and a length of $\sim 10 \mathrm{~mm}$. This ensured that the sample was fully accommodated within the field of view (FOV) of the X-ray $\mu$-CT system.

The as-deposited sample was exposed to thermal cycling using a cycling furnace (Model 1608 BL, CM Furnace Inc., UK.). Each thermal cycle comprised a 5 min heating ramp to $1150^{\circ} \mathrm{C}$, a $1 \mathrm{~h}$ dwell followed by forced air-cooling to ambient in $5 \mathrm{~min}$. The same region of interest (RoI) in the coupon was examined by X-ray $\mu$-CT after $0,10,50,100$ and 300 thermal cycles. In the meantime, in order to validate the X-ray $\mu$-CT results on this small matchstick sample, a larger reference coupon $(\sim 3 \mathrm{~mm}$ in cross-section diagonal and $\sim 10 \mathrm{~mm}$ in length) was cut from the same blade and subjected to the same thermal cycling regime. This coupon was used for cross-sectional SEM investigation.

X-ray $\mu$-CT was carried out using a Zeiss ${ }^{\circledR}$ Versa 500 3D X-ray microscope. The X-ray tube was operated at $90 \mathrm{kV}$ with a beam current of $\sim 70 \mu \mathrm{A}$ producing polychromatic X-rays. A lead-glass filter which absorbs photons with lower energies was used to achieve an optimal transmission rate and to reduce beam hardening. A $2 \mathrm{k} \mathrm{x} 2 \mathrm{k} 16$-bit CCD detector was used to record the projections. A 2 × 2 binning was employed to increase the counts in the projections thereby reducing the noise without having to increase the exposure time. Each scan comprised 2001 projections over a specimen rotation angle of $180^{\circ}$. An FDK (FeldkampDavis-Kress) algorithm [17] implemented within the XMReconstructor software provided by Zeiss $^{\circledR}$ was used for image reconstruction. The reconstructed virtual cross-sections have a voxel size of $0.85 \mu \mathrm{m}$. Subsequent image processing was undertaken using Avizo 9.0 and 
Matlab R2014. The data sets obtained at different stages were co-registered so that the same features were aligned and could be tracked.

The virtual cross-sections taken from the centre of the X-ray $\mu$-CT volumes acquired as a function of the number of thermal cycles are presented in Figure $\mathbf{1}$ alongside the corresponding cross-sectional SEM micrographs taken from the reference sample exposed to the same numbers of thermal cycles.

The topcoat appears to have more defects in the SEM images than in the CT virtual slices. Only relatively larger inter-column gaps can be seen in the CT slices and the fine cracks in the SEM images are not observed in part due to damage introduced during sample preparation for SEM and in part due to the higher spatial resolution in the SEM images.

A layer of oxide can be observed above the bond coat in the as-deposited state most likely due to process-induced oxidation. Even in the as-deposited state, imperfections exist in the TGO (see region denoted by the ellipse in Figure 1). The inter-diffusion zone (IDZ) appears the brightest in the CT virtual cross-sections as it is rich in Pt and refractory elements from the CMSX-4 superalloy substrate [27]. Such elements generally have a high X-ray mass attenuation coefficient. Dark inclusions are evident at the $\beta$-(Ni, Pt)Al/IDZ interface (labelled as $\mathrm{A}$ in Figure 1). Energy-dispersive X-ray spectroscopy (EDS) mapping confirms that these particles consist of $\mathrm{Al}$ and $\mathrm{O}$ as shown in Figure 2 (a). This confirms that such inclusions are corundum particles that have been embedded in the substrate during the grit-blasting processing prior to aluminizing [6].

Regions around the corundum particles (A in Figure 1 (a-c)) at the $\beta$-(Ni, Pt)Al/IDZ interface have changed little over the first 100 thermal cycles. However, after 300 thermal cycles, the corundum particle appears to be larger in size. Cross-section SEM image shows that voids 
can develop next to corundum particles as thermal cycling proceeds (see Figure 2). Therefore, it is likely that the enlargement of the corundum feature in figure 1 is due to void formation next to it.

Isolated voids are first found at the $\beta$-(Ni, Pt)Al/IDZ interface in the SEM image taken after 10 thermal cycles ( $\mathrm{C}$ in Figure 1 (f)). However, this could due to the loss of corundum particles during sample preparation. The formation of voids at this interface is evidenced by the CT virtual slices showing that voids have also initiated in what appear to be defect free regions with thermal cycling (B in Figure 1 (c) and (d)).

The IDZ initially has a very uneven interface with the substrate as is clear from both the SEM and CT image of the as-deposited sample. As thermal cycling proceeded, the fine precipitates in the IDZ are gone. This is accompanied by the formation of large particle-like and needlelike precipitates after 100 thermal cycles (Figure $1(\mathrm{~g})$ ). These are likely topologically closepacked (TCP) phases $[10,18,19]$. The needle-like precipitates then disappear with further thermal cycling, leaving behind the particle-like precipitates. It is noteworthy that the intrinsic imperfections in the TGO in the as-deposited sample have extended into the substrate with thermal cycling (ellipse in Figure 1).

The TGO thickness has been determined from both the SEM images and the CT virtual crosssections. To achieve a sub-pixel accuracy in TGO thickness measurement, we fitted the grey value profile across the TGO with a Gaussian function and the TGO thickness was taken as the full width at half maximum (FWHM) of the valley in the grey value profile (see [12]). Figure 3 (a) shows the change of TGO thickness as a function of the number of thermal cycles. For each step, 100 measurements were made at randomly picked locations. For the measurements on the CT virtual cross-sections, the same sample locations have been tracked throughout the whole cycling treatment. This precludes the influence of inhomogeneous TGO 
growth on TGO thickness measurement. It is evident from Figure 3 (a) that the analysis of CT virtual cross-sections and SEM cross-section give the same trends. The data from the CT sections have a slightly larger error bar due to their poorer spatial resolution $(0.85 \mu \mathrm{m} /$ pixel for a CT slice and $0.35 \mu \mathrm{m} /$ pixel for an SEM image). The TGO thickness follows a subparabolic growth law. The deviation from the parabolic law is in accordance with previous studies, where this has been ascribed to the retardation in grain boundary diffusion as the TGO grain size increases $[18,19]$.

Tracking of the spatial distribution of TGO, in particular the relative location of newlydeveloped TGO relative to pre-existing TGO (see Figure 3 (b)), were performed on the same cross-sections extracted from each CT scan in the time-lapse series. Figure 3 (c) plots the relative fraction of TGO that has formed above the pre-existing TGO (at topcoat/TGO interface) as a function of the number of thermal cycles. It can be seen that the TGO tends to develop faster beneath the pre-existing TGO (i.e. at the TGO/bond coat interface) than on top of it as thermal cycling proceeds. This is most likely because the rate of TGO thickening becomes dominated by inward diffusion of oxygen once a continuous $\alpha-\mathrm{Al}_{2} \mathrm{O}_{3}$ layer is formed [19].

The TGO/bond coat interface is investigated using time-lapse $\mu$-CT and the results are shown in Figure 4. The evolution of the root mean square roughness $\left(\mathrm{R}_{\mathrm{RMS}}\right)$ of the TGO/bond coat interface during thermal cycling is plotted in Figure 4 (f). It is evident from Figure 4 (f) that no significant global rumpling has occurred under the current test conditions. SEM images on the cross-section of the reference sample have given similar $\mathrm{R}_{\mathrm{RMS}}$ values to those determined from the $\mu$-CT virtual cross-sections. Similar to the TGO thickness measurement, results from the $\mu$-CT show larger scatter due to lower spatial resolution. Nevertheless, the roughness 
value and its evolution during thermal cycling is the same for both techniques and so the lack of rumpling is not the result of the small sample size used for the $\mu$-CT time-lapse study.

Time-lapse 3D observations on a section of the TGO/bond coat interface $\left(200 \times 250 \mu \mathrm{m}^{2}\right)$ are shown in Figure 4 (b-e) along with the interface profiles determined from the SEM crosssections (Figure $4(\mathrm{~g})$ ). Valleys and ridges can be seen at the interface. Moreover, the 3D profile of the interface is defined largely by the as-deposited profile. It has changed slightly in the first 10 thermal cycles remaining more or less unchanged thereafter.

As shown in Figure 4, there is no evidence of significant rumpling. Nevertheless, progressive roughening has been spotted in a certain location (e.g. ellipse in Figure 1). For this spot, the local undulation has been quantified using a half-cycle sinusoid having an amplitude of $A$ and a breath of $L / 2$. The change in amplitude during thermal cycling is plotted in Figure $4(\mathrm{~h})$.

The amplitude A (peak-to-valley) of the undulation in the TGO (shown in Figure 4 (h)) has increased from $\sim 5 \mu \mathrm{m}$ to $\sim 8 \mu \mathrm{m}$ within 290 thermal cycles. While the amplitude has increased the wavelength of the TGO undulation has remained largely the same. It is clear that this local TGO undulation has developed from a significant undulation in the bond coat surface of the as-deposited sample, which probably originated from the grit blasting treatment prior to depositing the YSZ topcoat. It is worth noticing that not all the significant TGO undulations have increased in amplitude during thermal cycling, for example (2) and (3) in Figure 4 (b).

In this study, the validity of studying small samples cut out from coated blades by X-ray $\mu$ CT to study the TGO growth and interface profile in an EB-PVD TBC with a $\beta-(\mathrm{Ni}, \mathrm{Pt}) \mathrm{Al}$ bond coat has been demonstrated against destructive cross-sectional SEM micrographs taken 
from larger samples at different stages of thermal cycling. By comparing the TGO and topcoat/TGO interface revealed by $\mu$-CT, the following conclusions can be drawn:

- The growth of the TGO under the current test conditions follows a sub-parabolic law ( $n \sim 0.4$ ) with increasing numbers of cycles.

- Particles retained from the grit blasting pre-treatment appear to be sites for increasing damage upon cycling

- The rate of growth of the TGO has been quantified at the TGO-bond coat interface and at the TGO-topcoat interface. Our results suggest that the TGO tends to form increasingly on the bond coat side of the TGO as thermal cycling proceeds.

- In the absence of global TGO rumpling, areas of undulation in the interface in the as-deposited coating can become increasingly pronounced with thermal cycling and could lead ultimately to critical coating defects. Identification of such local defects can be an important input for the lifetime prediction of an EB-PVD TBC system.

Besides corroborating the idea that undulations are a critical aspect of crack nucleation in TBC systems under thermal cycling, our CT/SEM cross correlations show that X-ray $\mu$-CT provides an accurate and non-destructive method for following damage in TBC systems as a function of thermal cycling.

\section{Acknowledgements}

The authors would like to acknowledge the assistance provided by the Henry Moseley X-ray Imaging Facility, which was funded in part by EPSRC (grants EP/F007906/1, EP/F001452/1 and EP/I02249X/1). PJW is grateful for a European Research Council for funding CORELCT under grant No 695638.

\section{Reference}

[1] D.R. Clarke, M. Oechsner, N.P. Padture, Mrs Bulletin 37 (2012) 891-902.

[2] N.P. Padture, M. Gell, E.H. Jordan, Science 296 (2002) 280-284.

[3] M.W. Chen, M.L. Glynn, R.T. Ott, T.C. Hufnagel, K.J. Hemker, Acta Materialia 51 (2003) 4279-4294.

[4] E.P. Busso, Z.Q. Qian, M.P. Taylor, H.E. Evans, Acta Materialia 57 (2009) 2349-2361. 
[5] V.K. Tolpygo, D.R. Clarke, Acta Materialia 52 (2004) 5115-5127.

[6] V.K. Tolpygo, D.R. Clarke, Acta Materialia 52 (2004) 5129-5141.

[7] V.K. Tolpygo, D.R. Clarke, K.S. Murphy, Surface \& Coatings Technology 188 (2004) 62-70.

[8] D.S. Balint, S.S. Kim, Y.F. Liu, R. Kitazawa, Y. Kagawa, A.G. Evans, Acta Materialia 59 (2011) 2544-2555.

[9] Y.H. Zhang, P.J. Withers, M.D. Fox, D.M. Knowles, Materials Science and Technology 15 (1999) 1031-1036.

[10] Y.H. Zhang, D.M. Knowles, P.J. Withers, Surface \& Coatings Technology 107 (1998) 76-83.

[11] T.L. Burnett, S.A. McDonald, A. Gholinia, R. Geurts, M. Janus, T. Slater, S.J. Haigh, C. Ornek, F. Almuaili, D.L. Engelberg, G.E. Thompson, P.J. Withers, Scientific Reports 4 (2014).

[12] E. Maire, P.J. Withers, International Materials Reviews 59 (2014) 1-43.

[13] Y. Zhao, A. Shinmi, X. Zhao, P.J. Withers, S. Van Boxel, N. Markocsan, P. Nylen, P. Xiao, Surface \& Coatings Technology 206 (2012) 4922-4929.

[14] S. Ahmadian, A. Browning, E.H. Jordan, Scripta Materialia 97 (2015) 13-16.

[15] D. Khoshkhou, M. Mostafavi, C. Reinhard, M.P. Taylor, D.S. Rickerby, I.M. Edmonds, H.E. Evans, T.J. Marrow, B.J. Connolly, Scripta Materialia 115 (2016) 100-103.

[16] C. Li, X. Zhang, Y. Chen, J. Carr, S. Jacques, J. Behnsen, M. di Michiel, P. Xiao, R. Cernik, Acta Materialia 132 (2017) 1-12.

[17] L.A. Feldkamp, L.C. Davis, J.W. Kress, Journal of the Optical Society of America aOptics Image Science and Vision 1 (1984) 612-619.

[18] D.K. Das, Progress in Materials Science 58 (2013) 151-182.

[19] C.M.F. Rae, M.S. Hook, R.C. Reed, Materials Science and Engineering a-Structural Materials Properties Microstructure and Processing 396 (2005) 231-239.

[20] J.A. Nychka, D.R. Clarke, Oxidation of Metals 63 (2005) 325-352.

[21] A.G. Evans, D.R. Clarke, C.G. Levi, Journal of the European Ceramic Society 28 (2008) $1405-1419$.

\section{Figure captions}

Figure 1: X-ray $\mu$-CT virtual cross-sections (LHS) showing a single RoI in the centre of the TBC at different stages of thermal cycling. SEM micrographs (RHS) have been recorded for sections taken from the larger reference TBC sample after exposure to the same numbers of thermal cycles. The ellipse and labels are referred to in the text.

Figure 2: SEM images showing corundum particles at the bond coat/IDZ interface: (a) asdeposited sample showing no defects surrounding the corundum particle and (b) sample after 150 thermal cycles showing void formation next to the corundum particle.

Figure 3: TGO development during thermal cycling: (a) thickness determined from SEM and CT cross-sections as a function of the number of thermal cycles; (b) Schematic showing the distribution of newly-formed TGO and (c) volume of TGO that forms in the topcoat side $\left(\mathrm{vol}_{\text {topcoat }}\right)$ divided by the total volume ( vol $\left._{\text {total }}\right)$ of newly-developed TGO.

Figure 4: TGO/bond coat interface roughness: (a) 3D volume showing the TBC sample and the interface in the region of interest; (b-e) 3D view of the interface at $0,10,100$ and 300 
thermal cycles where the colours represent the relative vertical height; (f) $R_{R M S}$ of the interface as a function of thermal cycle number determined from SEM cross-sections and $\mu$ CT virtual cross-sections; (g) Interface profiles extracted from cross-sectional SEM micrographs and $(\mathrm{h})$ variation in the amplitude $(A)$ of the undulation (1) in (b). 


\section{Figure1}

Click here to download high resolution image

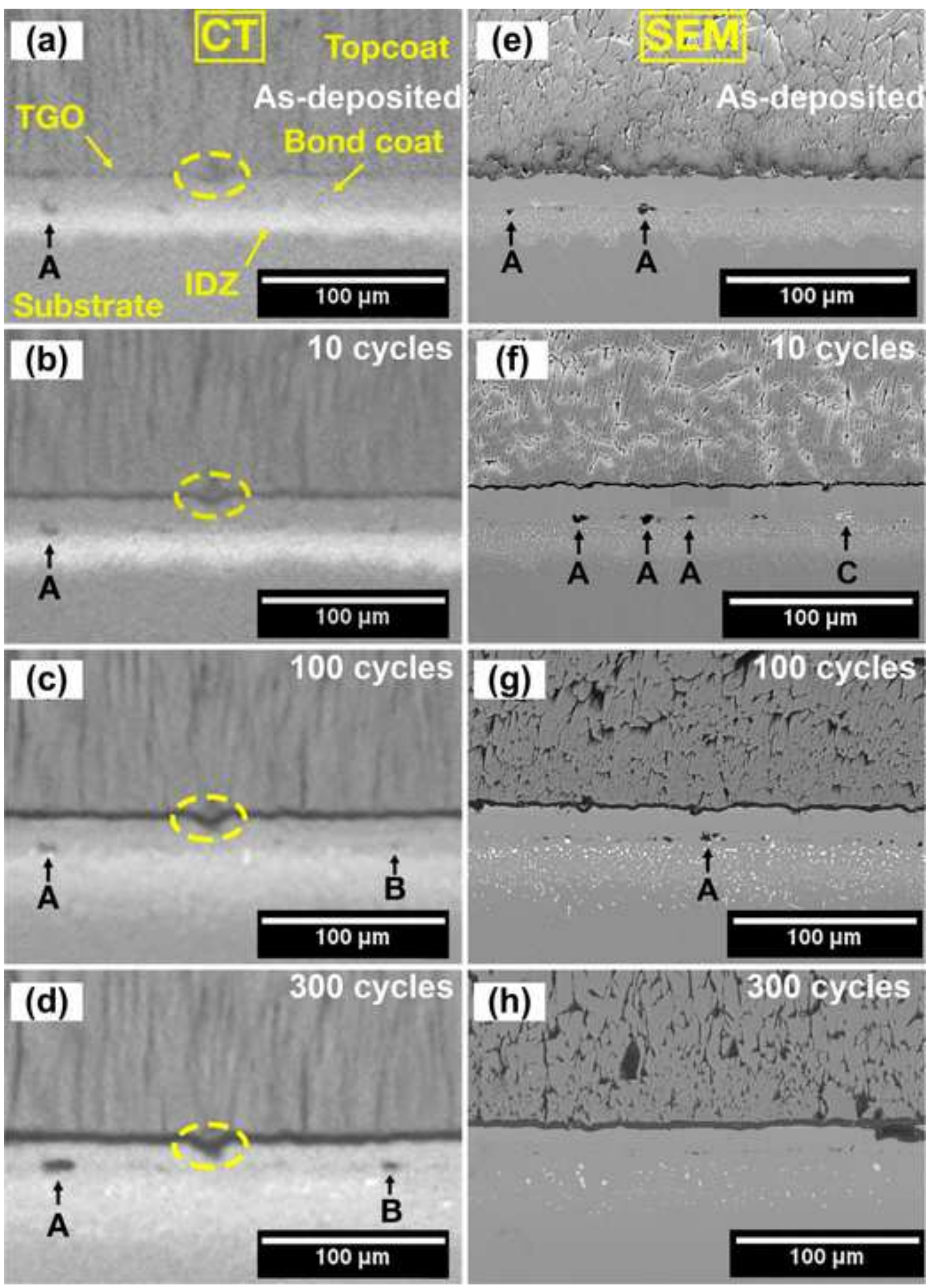


Click here to download high resolution image
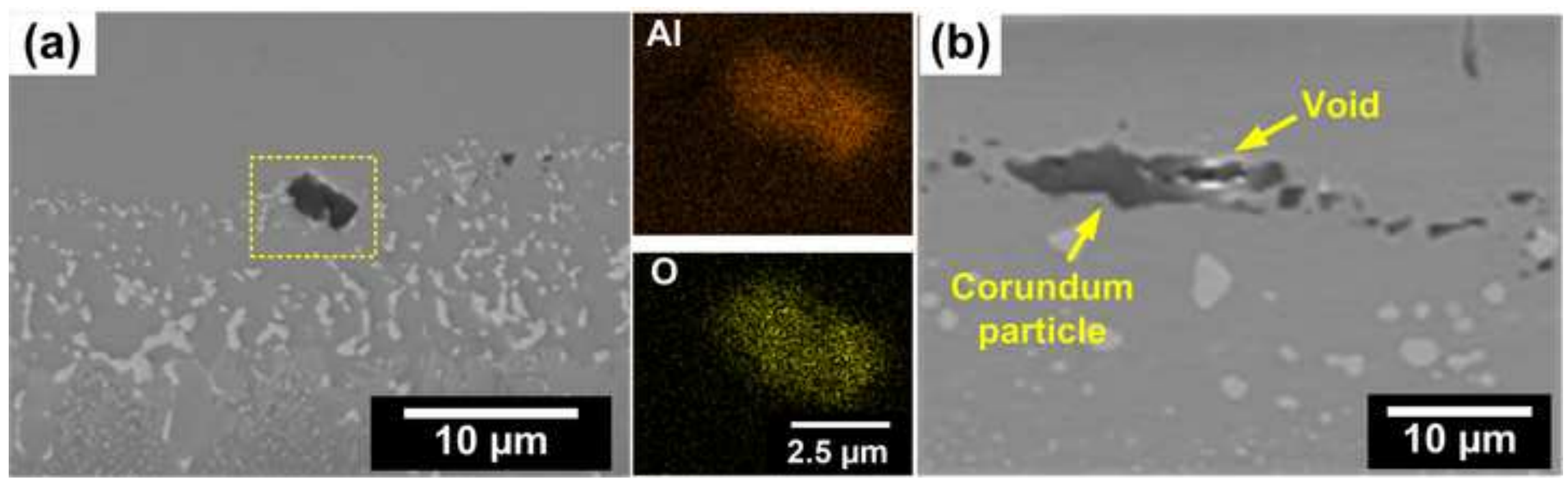
Click here to download high resolution image

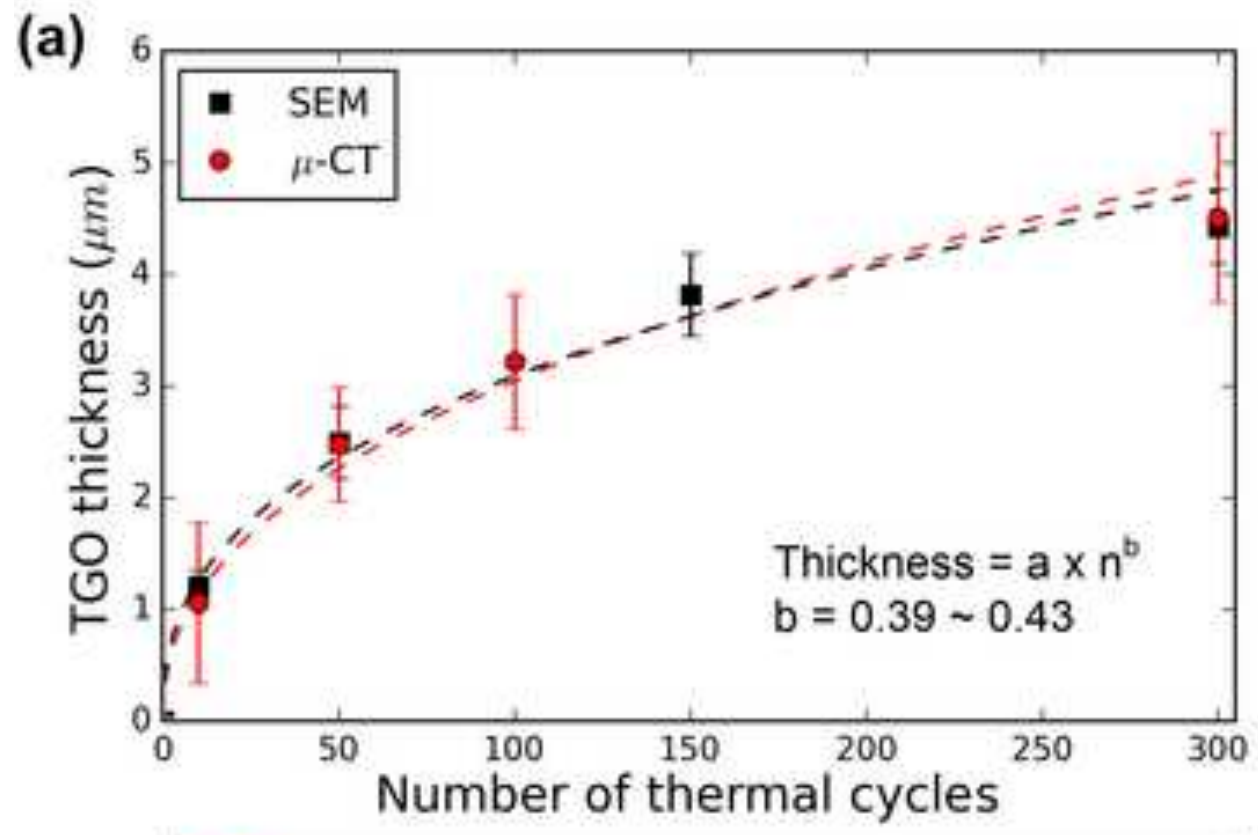

(b)

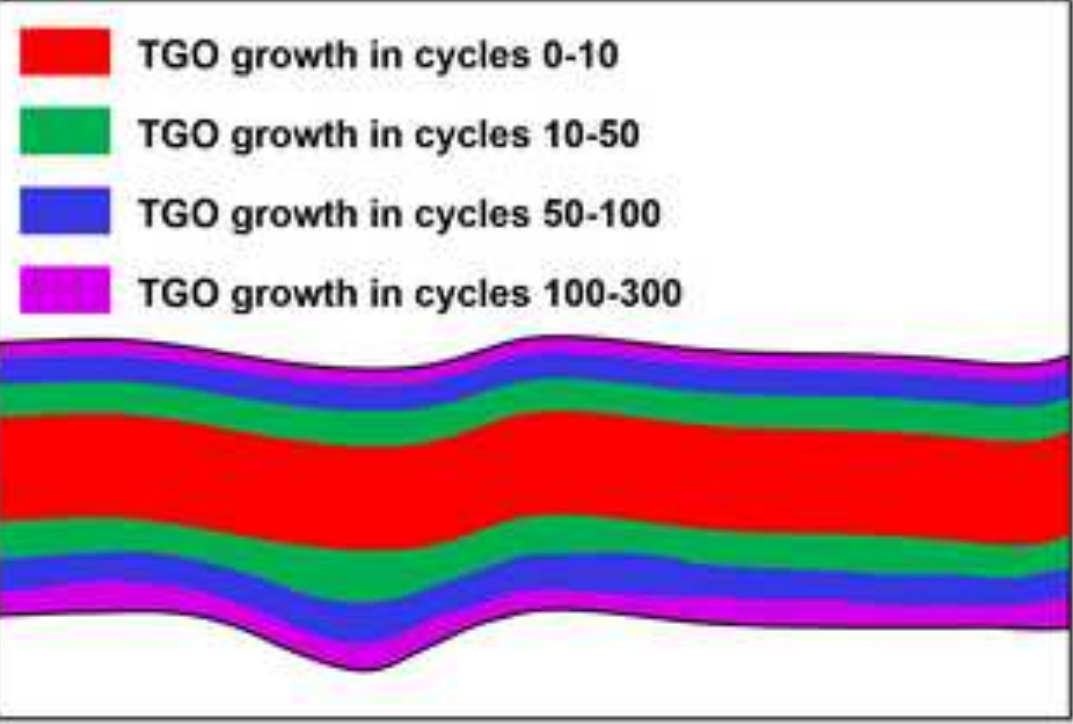

(c)

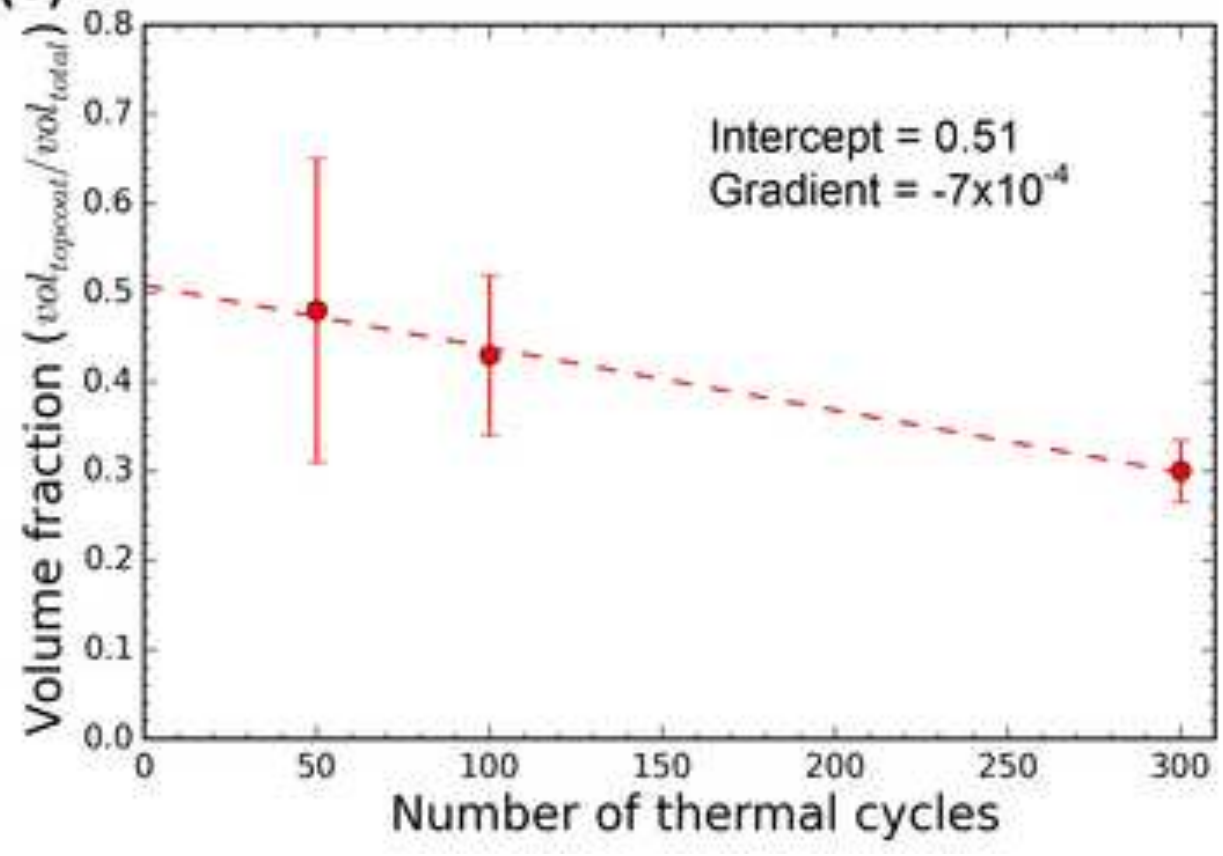


Click here to download high resolution image

(a)
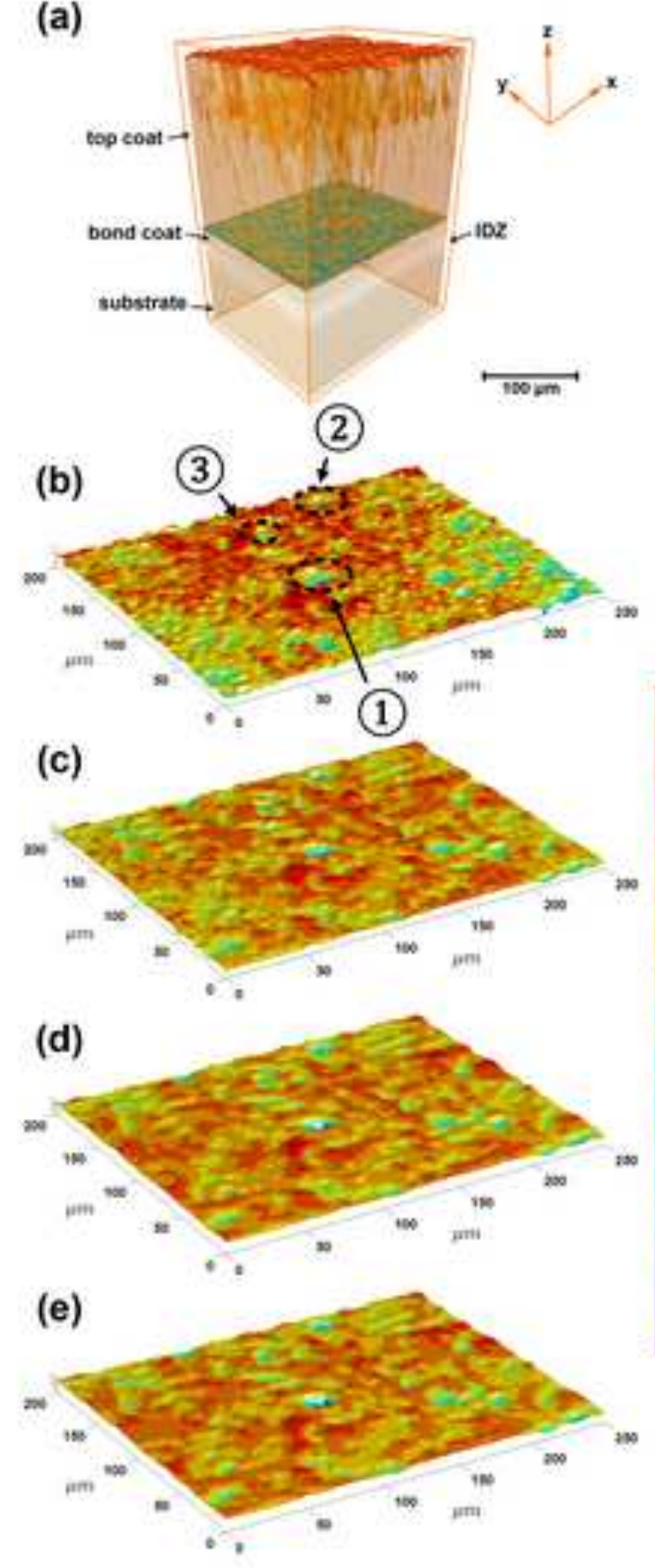

(f)

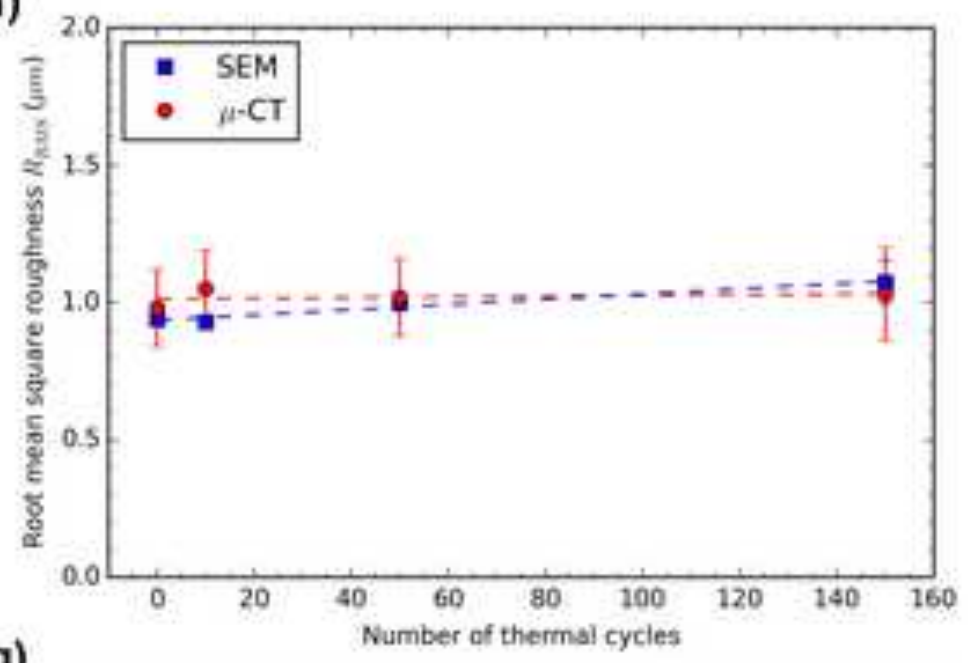

(g)

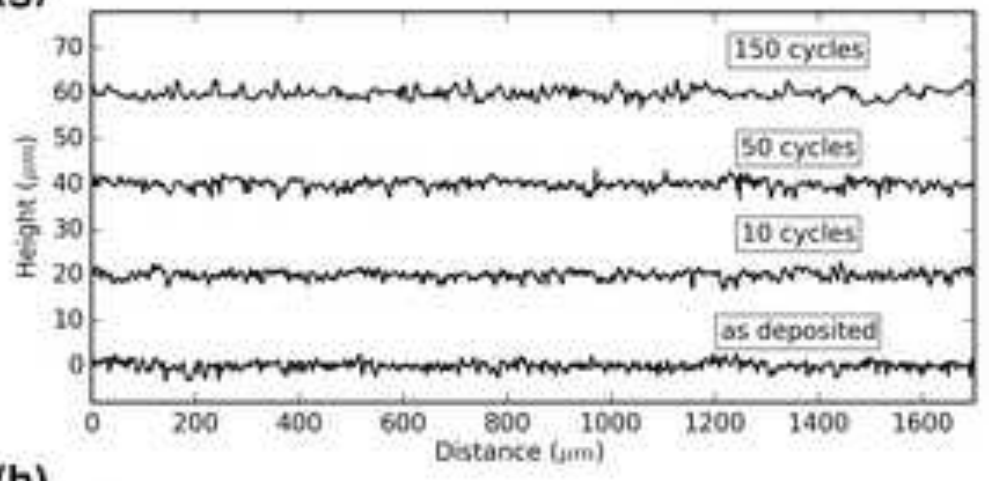

E (h)

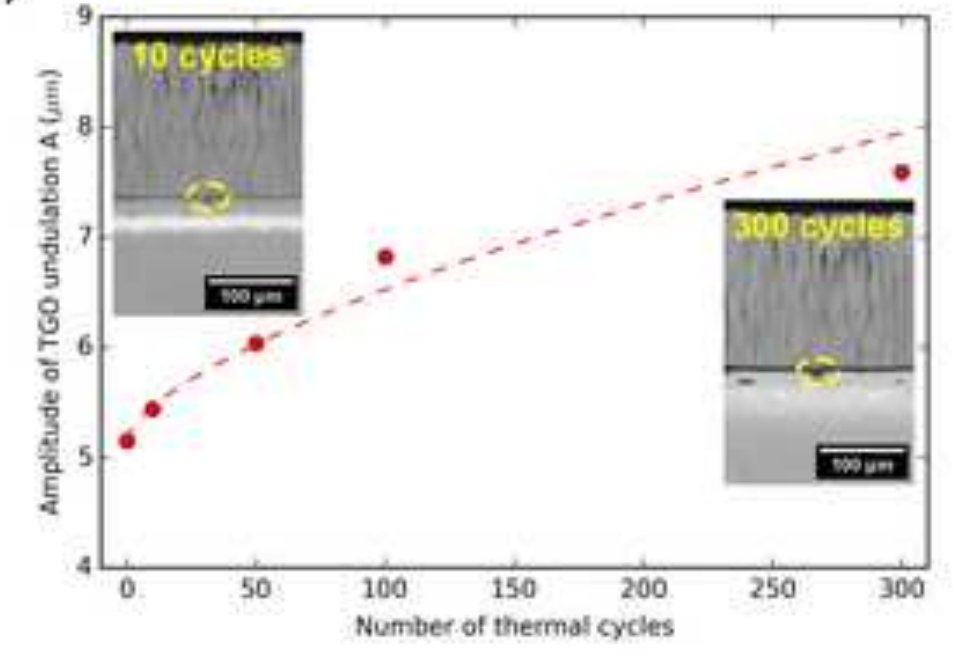

